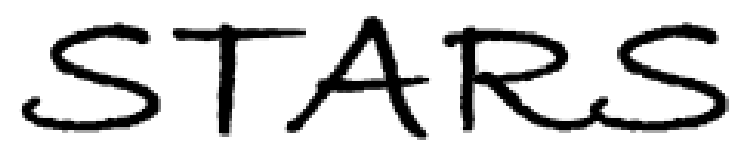

University of Central Florida

STARS

Faculty Scholarship and Creative Works

$10-1-2020$

\title{
Seeing Destinations Through Vlogs: Implications for Leveraging Customer Engagement Behavior to Increase Travel Intention
}

Yusi Cheng

University of Central Florida, yusicheng@knights.ucf.edu

Wei Wei

University of Central Florida, wei.wei@ucf.edu

Lu Zhang

Part of the Hospitality Administration and Management Commons, and the Tourism and Travel Commons

Find similar works at: https://stars.library.ucf.edu/ucfscholar

University of Central Florida Libraries http://library.ucf.edu

This Paper is brought to you for free and open access by STARS. It has been accepted for inclusion in Faculty Scholarship and Creative Works by an authorized administrator of STARS. For more information, please contact STARS@ucf.edu.

\section{Original Citation}

Cheng, Y., Wei, W., \& Zhang, L. (2020). Seeing destinations through vlogs: implications for leveraging customer engagement behavior to increase travel intention. International Journal of Contemporary Hospitality Management, 32(10), 3227-3248. https://doi.org/10.1108/IJCHM-04-2020-0319

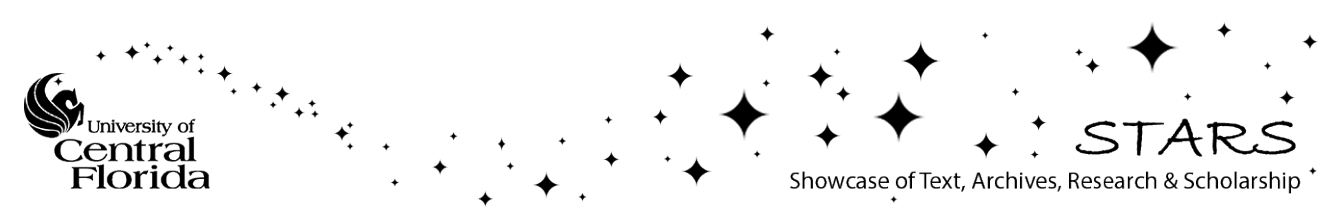


Cheng, Y., Wei, W., \& Zhang, L. (2020). Seeing destinations through vlogs: implications for leveraging customer engagement behavior to increase travel intention. International Journal of Contemporary Hospitality Management, 32(10), 3227-3248.

\title{
Customer Engagement Behavior in Travel Vlogs: Drivers and Consequence
}

\begin{abstract}
Purpose - This research aims to understand consumers' watching experience with travel vlogs as well as its impacts on customer engagement behavior (CEB) and travel intention. Drawing upon Theory of Resonance, this research incorporated both cognitive and emotional aspects of travel vlog watching experience.
\end{abstract}

Design/methodology/approach - This study employed multiple linear regression analysis. Data were collected from 352 participants who have watched travel vlogs over the past 12 months. Findings - The study results revealed positive impacts of source credibility, inspiration, escapism, and self-congruence on CEB, which further led to travel intention. Source credibility is the strongest predictor among all other constructs. In addition, more factors from emotional resonance influenced CEB compared to cognitive factors.

Research limitations/implications - For different types of destinations, the studied factors may weigh differently in driving people's experiences and behaviors. Future research can explore such potential variance.

Practical implications - Travel vloggers need to convey their intrinsic passion and enthusiasm through vlogs to create an emotional connection with the audiences. Destination marketers and hotel management are recommended to promote products by incentivizing audiences to engage with the travel vlogs.

Originality/value - No prior research examined the impacts of audiences' watching experiences on CEB in travel vlogs. This research fills this gap and contributes to the literature on tourism destination, media consumption, and customer engagement.

Keywords Customer engagement behavior, Travel vlogs, Theory of resonance, Travel intention, Experience

Paper type Research paper

\section{Introduction}


Marketers in hospitality and tourism industry endeavor to attract customers by applying innovative technologies (Law et al., 2019; Stamboulis and Skayannis, 2003). Travel vlogs (video blogs), as one of the most trending online video products, have received increasing business attention in recent years due to its attractiveness to audiences (Sara, 2016). Compared to blogs, travel vlogs mostly record vloggers' personal travel stories and personalized travel-related information in the form of videos rather than text and photo (Griffith and Papacharissi, 2010). Indeed, travel vlogs are the most popular type of travel videos watched on YouTube (Henderson, 2018). This type of video featured personal travel experiences and real-life stories, contributing to nearly half among all the travel subscriptions and receives four times more social engagement from the audience (Think with Google, 2014). As such, understanding consumers' experience of watching travel vlogs as well as its relationship with consumer engagement and purchase intention becomes a valuable topic for hospitality and tourism scholars and practitioners alike.

Past few years witnessed the growth of vlog-related research. With the advancement of online video sites (e.g. YouTube), common men are empowered to manage their self-making videos more efficiently, giving rise to the popularity of many professional and amateur vloggers. Studies that investigated vlogs from the perspective of vloggers have emerged about ten years ago, one of which introduced how vlogger's "presentation of self" was reflected in the modes and styles of the vlog (Griffith and Papacharissi, 2010). Later on, with increasing recognition of the commercial value of vlogs, video blogs started to be approached as an emerging marketing tool (Schouten et al., 2020). For instance, some studies found that vlogs (e.g. beauty vlogs and travel vlogs), in particular the images of the vloggers, significantly influenced consumer's decision-making process and purchase intention (Djafarova and Rushworth, 2017; Lodha and Philip, 2019; Rahmi et al., 2016).

Despite the extant literature tackling vlogs, this research identified two major research gaps. First, the majority of prior studies emphasized the direct link between vlogs and audiences' consequential behaviors, overlooking the potential underlying mechanism. In the context of travel vlogs, a vast amount of social engagement received by travel vlogs makes customer engagement behavior (CEB) a strong candidate to explain the relationship between travel vlogs watching experience and audiences' downstream behaviors. Prior studies mainly examined CEB in the context of social network platforms such as Facebook (Dessart et al., 2015; Kabadayi and Price, 2014), leaving travel vlogs a fertile ground for academic research along this line. Second, 
whereas recent studies have begun to investigate influencer marketing on social media (Glucksman, 2017; Lou and Yuan, 2019), limited research was conducted on online video websites such as YouTube (Xiao et al., 2018). Among the few exceptions, the majority focused on audiences' perceptions of influencers (e.g. influencers' credibility and homophily) (Sokolova and Kefi, 2019; Xiao et al., 2018), without providing a holistic picture of audiences' video/vlogwatching experience as well as its consequences.

To bridge the research gaps and to provide a better insight for travel vlogs, the authors aimed to explore how CEB, manifested by word-of-mouth (WOM) in the present research, bridge audiences' watching experiences and behavioral intention. The theory of resonance (Giorgi, 2017; McDonnell et al., 2017; Schudson,1989; Snow et al., 1986) was adopted as the theoretical cornerstone to help conceptualize watching experience of travel vlogs in both cognitive and emotional aspects. The objectives of this research were thus threefold: (1) to examine audiences' assessment of the cognitive and emotional resonances when watching travel vlogs; (2) to investigate the influence of cognitive and emotional resonance on CEB in travel vlogs; and (3) to test the impact of CEB on travel intention. Overall, the findings are expected to provide a more integrated view for explaining the influence of travel vlogs on prospective tourists. From a practical standpoint, this study would allow travel vloggers, destination marketers, and other industry stakeholders to gain a better understanding of the contributing factors of CEB in travel vlogs, with which they can be better equipped to more effectively develop strategies to attract tourists and to promote destinations.

\section{Literature Review}

\subsection{Travel vlogs in tourism}

The buzzword "vlog" is a neologism composed of the words "video" and "blog" (Pihlaja, 2014). Travel vlogs, featuring the characteristics of both travel videos and blogs, focus more on producers' personality and audiences' engagement (Sara, 2016). Previous data reports showed that travel videos play an essential role in customers' decision-making processes (Think with Google, 2016). For example, sixty-four percent of people would watch travel-related videos when planning a trip, and three in five travelers narrow down their travel-related choices after watching videos online (Think with Google, 2016). Travel vlogs, as the most popular type of travel videos watched on YouTube (Henderson, 2018), was found to render audiences a more 
entertaining viewing experience and produce more business opportunities for influencers or microcelebrities. Previous studies have examined the effects of microcelebrity endorsement on customers' hotel booking intentions (Zhang et al., 2019). Gretzel (2018) also pointed out the possibilities that firms or institutions can cooperate with influencers to promote hotel brands and destinations.

Due to their enormous marketing potential, travel vlogs have received growing attention from hospitality and tourism scholars. Recently, researchers started to examine the influence of travel vlogs on people's decision making. For example, Lodha and Philip (2019) conducted a qualitative study to explore how travel vlogs affected audiences and found that travel vlogs provide helpful information, which positively influences audiences' travel intention. Consistently, Tussyadiah and Fesenmaier (2009) investigated the role that travel videos play in the interest of potential travelers. They revealed that online travel videos can stimulate audiences' fantasies and daydreams, facilitate the recollection of their memories, and assist in audiences' trip planning through video sharing and information exchange. As travel vlogs are a type of travel videos (Think with Google, 2016), the empirical findings of travel videos may offer some insight for travel vlogs. As such, the inference that informative and attractive travel vlogs can benefit audiences in the decision-making process can be made although the underlying mechanism remains unclear. Compared to their "ancestors" (e.g. TV shows), travel vlogs are unique in the way that audiences engage with them due to its compelling content and sharable nature (Griffith and Papacharissi, 2010). Although audiences are often involved in travel vlogs through commenting and sharing, the important role of audiences' engagement behavior in travel vlogs remains understudied. To bridge this research gap, the present research sets to explore the factors influencing customer engagement behavior in travel vlogs as well as its consequence.

\subsection{Customer engagement behavior (CEB) in travel vlogs}

Customer engagement behavior (CEB) represents the behavioral dimension of customer engagement (CE) (Van Doorn et al., 2010), which is defined as a variety of customers' behavioral expressions that affect firms and brands (Van Doorn et al., 2010). Customer engagement (CE), subject to the context, has been widely conceptualized as a multidimensional construct (Baldus et al., 2015; Brodie et al., 2011; Hollebeek, 2011; So et al., 2014; Vivek, 2009). Brodie et al. (2011) proposed that CE is a combination of psychological state and 
behavioral participation, including three dimensions - cognitive, emotional, and behavioral. Despite the popularity of the three-dimensional perspective of CE, almost half of the definitions in both academic and business literature focused on the behavioral dimension (Brodie et al., 2011). Indeed, the emphasis on the behavioral dimension of CE is supported by the original meaning of "engage" in the Oxford Dictionary (1996), in which all the essential meanings of the verb indicate a behavioral focus (Van Doorn et al., 2010). The definition from Marketing Science Institute (MSI, 2010) also suggested CE as “a customers' behavioral manifestation toward a firm/brand beyond purchase, which results from motivational drivers including wordof-mouth activity, recommendations, customer-to-customer interactions, blogging, writing reviews, and other similar activities" (p. 4).

In this study, the authors focused on the behavioral dimension of $\mathrm{CE}-\mathrm{CEB}$ - by adopting audiences' word-of-mouth (WOM) as a prime manifestation of CEB in the context of travel vlogs. WOM is considered as one of the principal manifestations of CEB by a number of studies (Bijmolt et al., 2010; Choi and Kandampully, 2019; Van Doorn et al., 2010). For example, Oh, Roumani et al. (2017) recognized it as the most relevant and operational approach in examining the effect of CEB on the economic performance of US movies. As in other contexts, audiences' WOM toward travel vlogs could take place both online and offline. For instance, people can choose to recommend vlogs on social media and/or face-to-face. The present study viewed the construct WOM in a general perspective, including literal WOM, face-to-face conversations, and "word of mouse" known as online reviews (Berger, 2014).

\subsection{Drivers of CEB in travel vlogs: Theory of Resonance}

CEBs, such as WOM, can influence customers' purchase behaviors and contribute to firms' long-term reputation and brand recognition (Kumar et al., 2010; Van Doorn et al., 2010). To enhance firms' ability to predict customers' behaviors and future business performance, recent studies have begun to examine the drivers of CEB in different contexts such as social network sites and media-sharing sites (Islam et al., 2018; Kabadayi and Price, 2014; Khan, 2017; Munar and Jacobsen, 2014). For instance, Khan (2017) conducted a study to investigate the motives for YouTube user engagement behaviors in forms of users' liking, commenting, uploading, and sharing actions. Islam et al. (2018) examined self-brand image congruity and value congruity as significant drivers of CEB in online brand communities. 
Travel vlogs, as one particular type of travel videos, have received four times more social engagement from the audience than other types on YouTube do (Think with Google, 2014). However, travel vlogs have obtained scant attention from academic as of yet. Research related to CEB in travel vlogs, in particular, remains in its infancy, with few exceptions. For example, Lodha and Philip (2019) conducted an exploratory study to understand how travel vlogs influence students' decision-making of a trip. Regardless, the drivers of CEB in travel vlogs remain understudied. To fill the research gap and to advance the current knowledgebase of CEB, the present research was to first identify the drivers of CEB in travel vlogs. The theory of resonance (Giorgi, 2017; McDonnel et al., 2017; Snow et al., 1986), as delineated below, provided great insight into the conceptualization of the drivers of CEB in the context of travel vlogs.

Resonance is one of the most pervasive concepts adopted to describe a fit between a message and an audience's worldview (McDonnell et al., 2017). Derived from the sociology of culture, media, and social movements (Snow et al., 1986), resonance often depicts how cultural objects resonate with the life of audience (Schudson, 1989), and why some messages have an advantage over others (i.e. because they are congruent with audiences' viewpoints) (McDonnell et al., 2017). Previous literature introduced different types of resonance, such as cultural resonance (McDonnell, 2014; Schudson, 1989), frame resonance (Benford and Snow, 2000), and brand resonance (Keller, 2001; Keller, 2009). In organizational studies, resonance has been adopted to explain why certain framings are more effective than others are in accomplishing goals (Benford and Snow, 2000; Giorgi, 2017). Marketing scholars identified resonance as the depth of the psychological bond between customers and brands (Keller, 2009). In spite of the different explanations of what stimulates people's resonance, a large number of researchers agreed that resonance leads to positive outcomes. Snow et al. (1986) proposed that, in social movement organizations (SMOs), the higher the degree of frame resonance, the greater the probability that the framing effort will be successful. In marketing, researchers found that customers are more likely to share their experiences with a brand to others when they perceive a high level of resonance (Keller, 2001) which further contributes to sales (Keller, 2009).

The theory of resonance emphasizes both cognitive and emotional conditions of resonance (Giorgi, 2017; McDonnel et al., 2017). Most of the prior studies only considered either the cognitive or the emotional aspect of resonance, failing to systematically incorporate both. For 
example, frame resonance illustrated the degree to which a frame's values, beliefs, and ideas are important to actors' life (Benford and Snow, 2000), implying the significance of cognitive components of resonance (values and beliefs). Brand resonance referred to the nature of the relationship between customers and the brand and the degree to which customers feel they are "in sync" with the brand (Shang et al., 2017), pointing to the emotional bond contained in resonance. Recent studies have made some developments by articulating the two main resonance types: cognitive and emotional (Giorgi, 2017), in which cognitive resonance was based on the object's attraction to audiences' values, beliefs, and understandings, and emotional resonance was based on the arousal of audiences' feelings, passions, and aspirations. Both cognitive and emotional aspects can explain why an object may evoke resonance in some situations but not others (McDonnel et al., 2017). Some studies have started to apply the perspective of resonance to understand CEB. For example, in the context of social network sites, scholars found that consumers who have higher consumer resonance on social network sites (SNSs) tend to participate in online discussions (Shang et al., 2017). The current study thus adopted the theory of resonance as the theoretical cornerstone to identify the cognitive and emotional drivers of CEB.

\section{Cognitive resonance}

Prior research proposed that individuals can be inspired by values, understandings, and thoughtfulness conveyed by social media (Giorgi, 2017; Solis, 2010) and cognitive resonance is most likely to be achieved when people are able to interpret such values and understandings from the messages (Bail, 2016). Thus, in the context of travel vlogs, we identified three factors that assist audiences' interpretations as proxy of cognitive resonance: information acquisition, source credibility, and video quality. First of all, information acquisition would provoke audiences' cognitive resonance because through acquiring information, audiences obtained values, beliefs, and knowledge delivered by travel vlogs. Previous studies identified information acquisition as a significant driver of engagement behavior in different research fields (Berger, 2014; Khan, 2017). In the studies of media consumption, information acquisition was viewed as one of the most ancient and most important triggers of people's engagement (Palmgreen et al., 1980; Rafaeli, 1986). Khan (2017) conducted a study on social media by investigating 1143 users and revealed that the information-seeking motive can positively predict YouTube users' intention to 
engage in liking and disliking videos. Berger (2014) also pointed out information acquisition as one of the main motives of word-of-mouth intention. Therefore, in the context of travel vlogs, it is proposed that audiences are more likely to engage in a travel vlog when they can obtain ample and useful travel-related information.

In addition to information acquisition, source credibility, the expertise or trustworthiness perceived by individual audience as the likelihood of the spokesperson to provide credible information (Berlo et al., 1969; Bhattacherjee and Sanford, 2006; Burgoon and Hale, 1984; Zha et al., 2018) was chosen as another cognitive driver of CEB. Benford and Snow (2000) found that the credibility of the proffered frame accounts for the variation in the degree of frame resonance, in which the credibility of the frame "articulators" or "claimsmakers" played a significant role. This finding echoes Wilson's (1983) theory of cognitive authority as well as Rieh and Danielson's explanation (2007), both of which argued that people only consider those "who are deemed to know what they are talking about" as cognitive authorities. Previous research on influencer marketing has found that the credibility of these "micro-endorsers" (as compared to "bigger" celebrity endorsers) significantly affects consumers (Hall, 2015; Schouten et al., 2020; Xiao et al., 2018). Communication scholars also contended that audiences are more likely to be persuaded by speakers who are recognized as more credible (Hovland and Weiss, 1951; Wheeless et al., 2011). In the context of the present study, travel vloggers by the same token, could play the role of "articulators" or "micro-endorsers" in influencing audiences" behaviors. Prior studies have demonstrated that source credibility is an essential factor that reduces audiences' distrust of incomplete or manipulative information and leverages audiences' participation in blog-mediated communication (Scoble and Israel, 2006). In Yang et al.'s (2010) experimental study, they also found that bloggers' credibility positively enhances the audiences' engagement in crisis communication. Thus, in the context of travel vlogs, we argued that the credibility of travel vloggers will significantly influence their audiences' engagement behavior, such that the more credible a vlogger is perceived, the more likely the audiences would further engage with the travel vlog, and vice versa.

In conjunction with the factors mentioned above, McDonnel et al. (2017) advocated that the quality of the encounter between audiences and cultural objects can help people to understand how resonance happens. Thus, video quality is assessed as another factor that bolsters audiences' CEB when they are watching travel vlogs. Video quality describes audiences' cognitive 
evaluation of video's loading time, image quality, and flow (Dobrian et al., 2011). Prior scholars found that good quality of an online product (e.g. a website) will influence customers' interaction with firms and their eWOM engagement (McKnight et al., 2002; Yusuf and Busalim, 2018). Similarly, when people are browsing travel vlogs, the quality of the videos can significantly affect their experiences and behaviors. Therefore, it is posited that travel vlogs with clearer images, shorter loading time, and smoother flow will foster audiences' tendency to further engage with it.

On the basis of the discussions above, Hypotheses 1a-1c are formulated as follows:

Hypothesis 1. (a) Information acquisition, (b) Source credibility, and (c) Video quality will have a positive impact on CEB in travel vlogs.

\section{Emotional resonance}

In addition to cognitive resonance, resonance is also deeply rooted in emotions (McDonnell et al., 2017). Previous researchers found that emotional resonance stems from emotional states (Polletta, 2006) and illustrates a sense of alignment of a frame with the audiences' feelings, passions, desires, and aspirations (Giorgi, 2017). Travel vlogs are often characterized by their emotional aspect, such as enjoyable, entertaining, and appealing (NCMA, 2018). Meanwhile, the coherence of audiences' self-evaluation and the image of the consuming objects (e.g. brands and products) is also crucial for arousing the emotional responses (Han and Back, 2008). Thus, the present study operationalized audiences' emotional resonance with travel vlogs into four constructs, namely entertainment (Khan, 2017; Lee and Ma, 2012; Pine and Gilmore, 1998), inspiration (Böttger et al., 2017; Elliot, 1997; Kim and Fesenmaier, 2008), escapism, (Hosany and Witham, 2010; Papacharissi and Mendelson, 2011), and self-congruence, (Khan, 2017; Park et al., 2009; Sirgy and Su, 2000).

Audiences are more likely to engage with entertained products because sharing funny things makes the sharers seem interesting (Berger, 2014). Consistent with this viewpoint, previous studies demonstrated entertainment as one of the prominent predictors of CEB (Khan, 2017; Lee and Ma, 2012; Park et al., 2009). Park et al. (2009) gauged entertainment as one of the principal motives of users to join Facebook groups. Nov et al. (2010) also viewed entertainment as an essential motivation encouraging users' photo-sharing behavior in an online community. In the 
present study, it is presumable to propose that audiences are more willing to recommend travel vlogs that make them feel entertained, relaxed, and pleasant.

Inspiration is defined as an infusion of beliefs stimulated by truth, goodness, or beauty (Elliot, 1997; Kim and Fesenmaier, 2008; Thrash and Elliot, 2003). Previous research revealed that online videos can provide enthusiasm to audiences by stimulating appealing fantasies and daydreams, as well as bringing back past travel memories (Tussyadiah and Fesenmaier, 2009). Others demonstrated that tourist inspiration leads to behavioral consequences such as recommendation intentions and loyalty (e.g. Böttger et al., 2017). In the context of travel vlog, this study proposed that audiences are more inclined to engage with travel vlogs that arouse unforgettable travel memories and vivid imaginations.

Escapism is demonstrated as an escapist experience when an individual is fully immersed and absorbed in an activity (Csikszentmihalyi, 1990; Hosany and Witham, 2010). Escapism from the stress and tedium of everyday life was recognized as a significant factor influencing consumer behaviors (Holmqvist et al., 2019; Papacharissi and Mendelson, 2011). Papacharissi and Mendelson (2011) conducted a qualitative study and found that the desire for detaching oneself from everyday hassles is a vital motivation of participants to engage with Facebook. Holmqvist et al. (2019) also pointed out that escapism encourages consumers to engage in luxury consumption. The present research advocated that the more a travel vlog can help audiences to be disconnected from daily routines, the more likely they are to engage with the travel vlog by recommending it to others.

Self-congruence denotes the match of an individual's self-concept with another productuser's image (Sirgy and Su, 2000). Engagement theory asserts that the congruence of one's personal and others' values or the agreement with others' preferred identity and image will enhance people's engagement (Kahn, 1990; Rich et al., 2010). In the context of travel vlogs, travel vloggers represent other visitors who have been to the destination promoted in the vlogs. Thus, the image of travel vloggers plays an iconic role in forming audiences' self-congruence. In an online environment (e.g. a social media platform such as Facebook or YouTube), literature found that customers' self-congruence positively influences their engagement in online brand communities (Islam et al., 2018). Therefore, in this study, the congruence between the actual/desired image of audiences and that of travel vloggers could drive audiences' engagement behaviors. 
On the basis of these discussion, the authors put forward Hypotheses $2 \mathrm{a}-2 \mathrm{~d}$ as follows:

Hypothesis 2. (a) Entertainment, (b) Inspiration, (c) Escapism, and (d) Self-congruence will have a positive impact on CEB in travel vlogs.

\subsection{Consequence of CEB in travel vlogs: travel intention}

Travel intention is a type of behavioral intentions that underlines ones' commitment to travel (Jang et al., 2009). Travel intention is interpreted as a rational appraisal of the costs and benefits among all alternatives as a result of a mental process that transforms motivation into behavior (Chen et al., 2014; Jang et al., 2009). Prior scholars have examined the positive relationship between CEBs and consumers' behavioral intention (Ahn and Back, 2018; Kang, 2014; Yusuf and Busalim, 2018). For example, a previous study on the engagement of mobile travel applications demonstrated that if a user spent more effort on a travel app, he/she would be more willing to exhibit behavioral engagement intentions such as continuance usage and participation intention (Fang et al., 2017). Similarly, in the context of this study, when one is more willing to invest time and energy in recommending a travel vlog as a way to engage with it, he/she likely will be more inclined to visit the travel destination as introduced in the vlog. Hypothesis 3 was put forward as follows:

Hypothesis 3. CEB in travel vlogs will have a positive impact on travel intention.

The conceptual model of the present study is presented in Fig. 1.

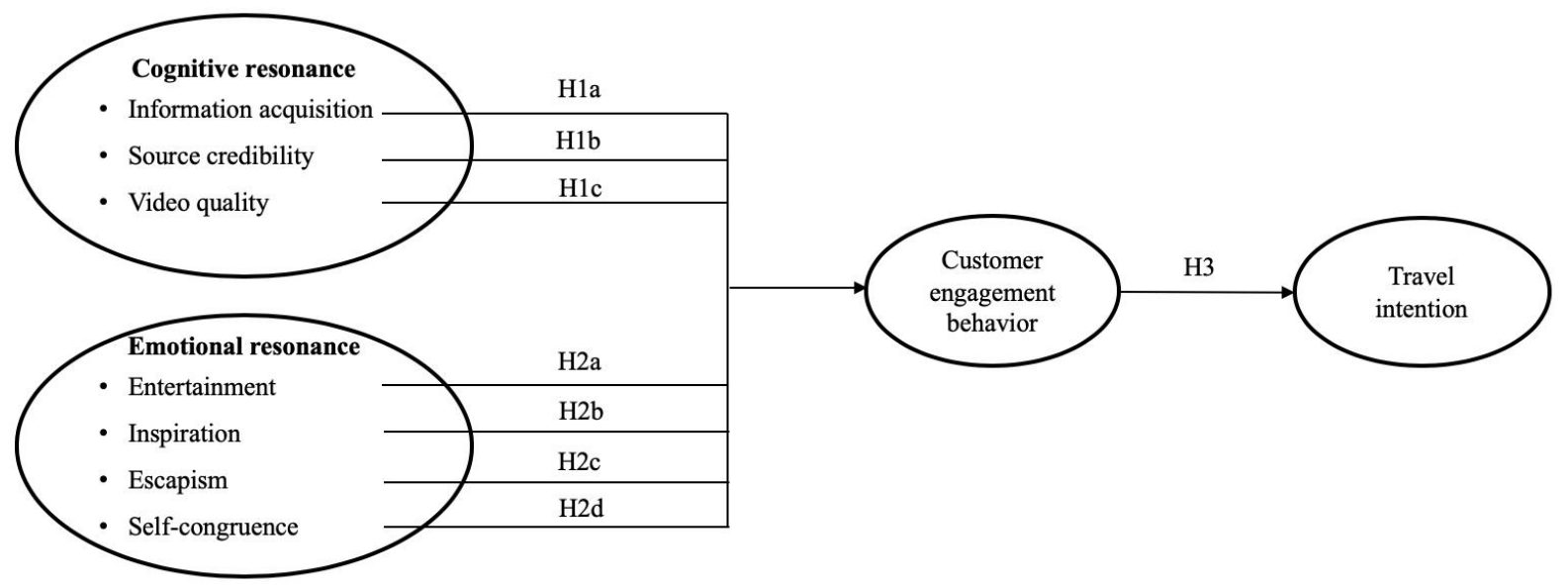


Fig. 1. Proposed conceptual model.

\section{Methodology}

\subsection{Procedure and sample}

Previous research on travel vlogs/videos and customer engagement provided well-established scales to measure audiences' watching experiences, CEBs, and travel intention. This research thus followed a quantitative methodology for hypotheses testing by using an online survey. Participants were recruited from Amazon Mechanical Turk (MTurk), which is an online platform that recruits large and diverse workers to complete tasks such as answering surveys (Buhrmester et al., 2011). MTurk is recognized to provide valid and reliable data with demographic diversity (Buhrmester et al., 2011).

A cover page was posted in the MTurk platform to explain the research purpose, importance, assurance of confidentiality, and directions on how to respond to the questions. Following the cover page, a brief introduction on travel vlog and vloggers was provided, including a screenshot from one of the popular travel vlogs on YouTube as an example to help respondents recall their own watching experience. Then, two screening questions were prepared to select participants who were 18 years old or above and had the experience of watching travel vlogs in the past 12 months. People who answered "no" for the screening questions were automatically directed to the end of the questionnaire and were not able to complete the survey. A total of 413 questionnaires was collected and 352 valid responses were retained for data analysis.

\subsection{Questionnaire and measurements}

The questionnaire consisted of four parts. The first part collected information about participants' most memorable travel vlog watching experience, including the name of the destination, the identity of the vlogger (e.g. name, celebrity or not), the length of the video, and the reason why it was so memorable. These questions were presented to strengthen participants' memory of the recalled experience to obtain data with greater accuracy.

The second part of the questionnaire collected participants' subjective experience of watching travel vlogs they recalled in the first part. Previous studies on online shared videos and travel vlogs provided scales for measuring the cognitive experience of watching travel vlogs (e.g. Bhattacherjee and Sanford, 2006; Dobrian et al., 2011; Khan, 2017), namely information 
acquisition (4 items such as "I got travel information that interested me"), video quality (4 items such as "The loading time of the vlog was short"), and source credibility (4 items such as "The vlogger was trustworthy/authentic, knowledge, and credible"). Based on previous studies regarding the emotional aspect of experiences (e.g. Hosany and Witham, 2010; Lee and Ma, 2012), emotional resonance was measured by entertainment (4 items such as "Watching the travel vlog helped me to pass time/relax"), inspiration (3 items such as "Watching the travel vlog inspired me to visit the destination"), escapism (4 items such as "The watching experience let me image being somewhere else"), and self-congruence ( 4 items such as "The image of the travel vlogger was consistent with how I see myself'). The three-item scale of CEB in the context of this study was adapted from Jung and Seock (2017) (such as "I would recommend this vlog to my friends").

The third part of this questionnaire measured audiences' travel intentions. The four-items scale was adapted from Mohammed Abubakar (2016), including statements such as "I will visit the destination in the vlog". An attention check question was added in this section by asking respondents to select "Neither agree nor disagree".

All items were measured by a seven-point Likert-type scale (strongly disagree as 1 and strongly agree as 7). Items were randomized to avoid potential bias. Participants' demographic information was collected at the end, consisting of their gender, age, level of education, marital status, household income, ethnicity, and employment status.

\subsection{Data analysis}

The data were thoroughly screened and cleaned prior to the main analysis. Participants who failed to answer the attention check questions correctly and who had uniform answers for a large number of or all items were eliminated. Statistical Package for Social Science (SPSS) version 24 was adopted in the analysis process. The reliability and validity of each construct were examined followed by linear regression analyses for hypotheses testing.

\section{Results}

\subsection{Sample profile}

The demographic information of the respondents is summarized in Table 1. A total of 352 valid responses were included in the data analysis. Sixty three percent of the participants were male 
and $58.5 \%$ were aged between $26-40$. The percentage of the married (48.8\%) was nearly equal to that of the single (48.6\%). Approximately half of the respondents held a bachelor's degree (54\%). The majority were Caucasian (69.8\%) and 76.7\% were employed for salary/wages.

Table 1

Sample characteristics.

\begin{tabular}{|c|c|c|}
\hline Characteristics & Frequency & Percent \\
\hline \multicolumn{3}{|l|}{ Gender } \\
\hline Male & 222 & $63 \%$ \\
\hline Female & 128 & $36.4 \%$ \\
\hline Prefer not to disclose & 2 & $0.6 \%$ \\
\hline \multicolumn{3}{|l|}{ Age } \\
\hline $18-25$ & 51 & $14.5 \%$ \\
\hline $26-40$ & 206 & $58.5 \%$ \\
\hline $41-60$ & 80 & $22.7 \%$ \\
\hline Over 60 & 14 & $4.0 \%$ \\
\hline Prefer not to disclose & 1 & $0.3 \%$ \\
\hline \multicolumn{3}{|l|}{ Education } \\
\hline High school or less & 45 & $12.8 \%$ \\
\hline College or associate degree & 65 & $18.4 \%$ \\
\hline Bachelor degree & 190 & $54 \%$ \\
\hline Master degree & 43 & $12.2 \%$ \\
\hline Doctoral degree & 7 & $2 \%$ \\
\hline Other & 1 & $0.3 \%$ \\
\hline Prefer not to disclose & 1 & $0.3 \%$ \\
\hline \multicolumn{3}{|l|}{ Marital status } \\
\hline Single & 171 & $48.6 \%$ \\
\hline Married & 172 & $48.8 \%$ \\
\hline Other & 8 & $2.3 \%$ \\
\hline Prefer not to disclose & 1 & $0.3 \%$ \\
\hline \multicolumn{3}{|l|}{ Household income } \\
\hline Less than $\$ 20,000$ & 37 & $10.5 \%$ \\
\hline$\$ 20,000-\$ 50,000$ & 128 & $36.4 \%$ \\
\hline$\$ 50,001-\$ 100,000$ & 139 & $39.5 \%$ \\
\hline$\$ 100,001-\$ 200,000$ & 39 & $11.1 \%$ \\
\hline More than $\$ 200,000$ & 5 & $1.4 \%$ \\
\hline Prefer not to disclose & 4 & $1.1 \%$ \\
\hline \multicolumn{3}{|l|}{ Ethnicity } \\
\hline Asian & 31 & $8.9 \%$ \\
\hline Black/African & 43 & $12.3 \%$ \\
\hline Caucasian & 246 & $69.8 \%$ \\
\hline Hispanic/Latinx & 16 & $4.6 \%$ \\
\hline Native American & 10 & $2.7 \%$ \\
\hline Others & 4 & $1.1 \%$ \\
\hline Prefer not to disclose & 2 & $0.6 \%$ \\
\hline
\end{tabular}




\begin{tabular}{lll}
\hline A student & 7 & $2 \%$ \\
Employed for salary/wages & 270 & $76.7 \%$ \\
Self-employed & 47 & $13.4 \%$ \\
Out of work & 14 & $4 \%$ \\
Retired & 6 & $1.7 \%$ \\
Other & 4 & $1.1 \%$ \\
Prefer not to disclose & 4 & $1.1 \%$ \\
\hline
\end{tabular}

\subsection{Test for reliability and validity}

The alpha values of all constructs ranged from 0.72 to 0.92 (information acquisition $=0.72$;

video quality $=0.84$; source credibility $=0.90$; entertainment $=0.77$; inspiration $=0.80$;

escapism $=0.83$; self-congruence $=0.92 ; \mathrm{CEB}=0.92$; travel intention $=0.86$ ), which were all higher than the suggested cutoff of 0.70 (Bagozzi and Yi, 1988), indicating the reliability of each construct. Construct validity was evaluated through examining the correlations among variables. The results suggested that 35 out of 36 correlations were statistically significant and were greater or equal to $\mathrm{r}=0.24$ ( $\mathrm{p}<.01$, two-tailed), indicating positive correlations between each two variables besides video quality and self-congruence $(r=0.07, p>.01)$. Among all the correlations, the association between source credibility and CEB had the strongest correlation ( $\mathrm{r}$ $=0.7, \mathrm{p}<.01)$. Table 2 presents the correlations, means, and standard deviation.

Table 2

Correlations (squared correlations), mean, and standard deviation.

\begin{tabular}{|c|c|c|c|c|c|c|c|c|c|}
\hline & IA & VQ & SO & EN & IN & $\mathrm{ES}$ & $\mathrm{SC}$ & CEB & $\mathrm{TI}$ \\
\hline IA & 1.00 & & & & & & & & \\
\hline VQ & $.29 * *$ & 1.00 & & & & & & & \\
\hline SO & $.49 * *$ & $.55 * *$ & 1.00 & & & & & & \\
\hline $\mathrm{EN}$ & $.34 * *$ & $.51 * *$ & $.54 * *$ & 1.00 & & & & & \\
\hline IN & $.60 * *$ & $.53 * *$ & $.66 * *$ & $.59 * *$ & 1.00 & & & & \\
\hline ES & $.51 * *$ & $.24 * *$ & $.44 * *$ & $.34 * *$ & $.52 * *$ & 1.00 & & & \\
\hline $\mathrm{SC}$ & $.43 * *$ & .07 & $.43^{* *} *$ & $.20 * *$ & $.36 * *$ & $.39 * *$ & 1.00 & & \\
\hline CEB & $.49 * *$ & $.37 * *$ & $.70 * *$ & $.43 * *$ & $.61 * *$ & $.49 * *$ & $.50 * *$ & 1.00 & \\
\hline $\mathrm{TI}$ & $.43 * *$ & $.29 * *$ & $.41 * *$ & $.28 * *$ & $.62 * *$ & $.41 * *$ & $.49 * *$ & $.511 * *$ & 1.00 \\
\hline Mean & 5.35 & 6.03 & 5.87 & 5.78 & 5.82 & 5.26 & 4.68 & 5.48 & 5.43 \\
\hline Std. Dev. & 1.01 & .94 & 1.01 & .90 & .99 & 1.20 & 1.40 & 1.33 & 1.17 \\
\hline
\end{tabular}

Note:

Correlation is significant at the 0.01 level (two-tailed).

$\mathrm{IA}=$ information acquisition, $\mathrm{VQ}=$ video quality, $\mathrm{SO}=$ source credibility, $\mathrm{EN}=$ entertainment, $\mathrm{IN}=$ inspiration, ES = escapism, $\mathrm{SC}=$ self-congruence, $\mathrm{CEB}=$ customer behavior engagement, $\mathrm{TI}=$ travel intention. Mean values are based on seven-point scales.

\subsection{Hypotheses testing}


A multiple linear regression was performed in this study to examine H1 and H2. Seven variables (information acquisition, video quality, source credibility, entertainment, inspiration, escapism, and self-congruence) were entered as independent variables and CEB was entered as the dependent variable. All IVs were entered at once. The model was statistically significant $\left(\mathrm{F}_{(7}\right.$, $344)=67.74, \mathrm{p}<.001)$ and accounted for approximately $58 \%$ of the variance of CEB $\left(\mathrm{R}^{2}=0.58\right.$, Adjusted $\left.\mathrm{R}^{2}=0.571\right)$. Specifically, source credibility $(\beta=0.43, \mathrm{t}=8.01, \mathrm{p}<.001)$, inspiration $(\beta$ $=0.19, \mathrm{t}=3.32, \mathrm{p}=0.001)$, escapism $(\beta=0.11, \mathrm{t}=2.48, \mathrm{p}<.05)$, and self-congruence $(\beta=0.19$, $\mathrm{t}=4.57, \mathrm{p}<.001$ ) were found to be significant predictors of CEB. H1(c), H2 (b), H2(c), and $\mathrm{H} 2(\mathrm{~d})$ were supported. Information acquisition $(\beta=0.03, \mathrm{t}=0.71, \mathrm{p}=0.48)$, video quality $(\beta=$ $0.03, \mathrm{t}=-0.62, \mathrm{p}=0.53)$, and entertainment $(\beta=0.02, \mathrm{t}=0.54, \mathrm{p}=0.59)$ did not have $\mathrm{a}$ significant impact on CEB. Thus, H1(a), H1(b), and H2(a) were not supported.

A simple linear regression was conducted to test the relationship between CEB and travel intention. Results indicated that CEB has a positive impact on travel intention $(\beta=0.51, \mathrm{t}=$ $11.12, \mathrm{p}<.001)$. The $26.1 \%$ of the variation in customers' travel intention can be explained by CEB $\left(\mathrm{R}^{2}=0.261\right)$. Therefore, H3 was supported. Results were visualized in Fig. 2.

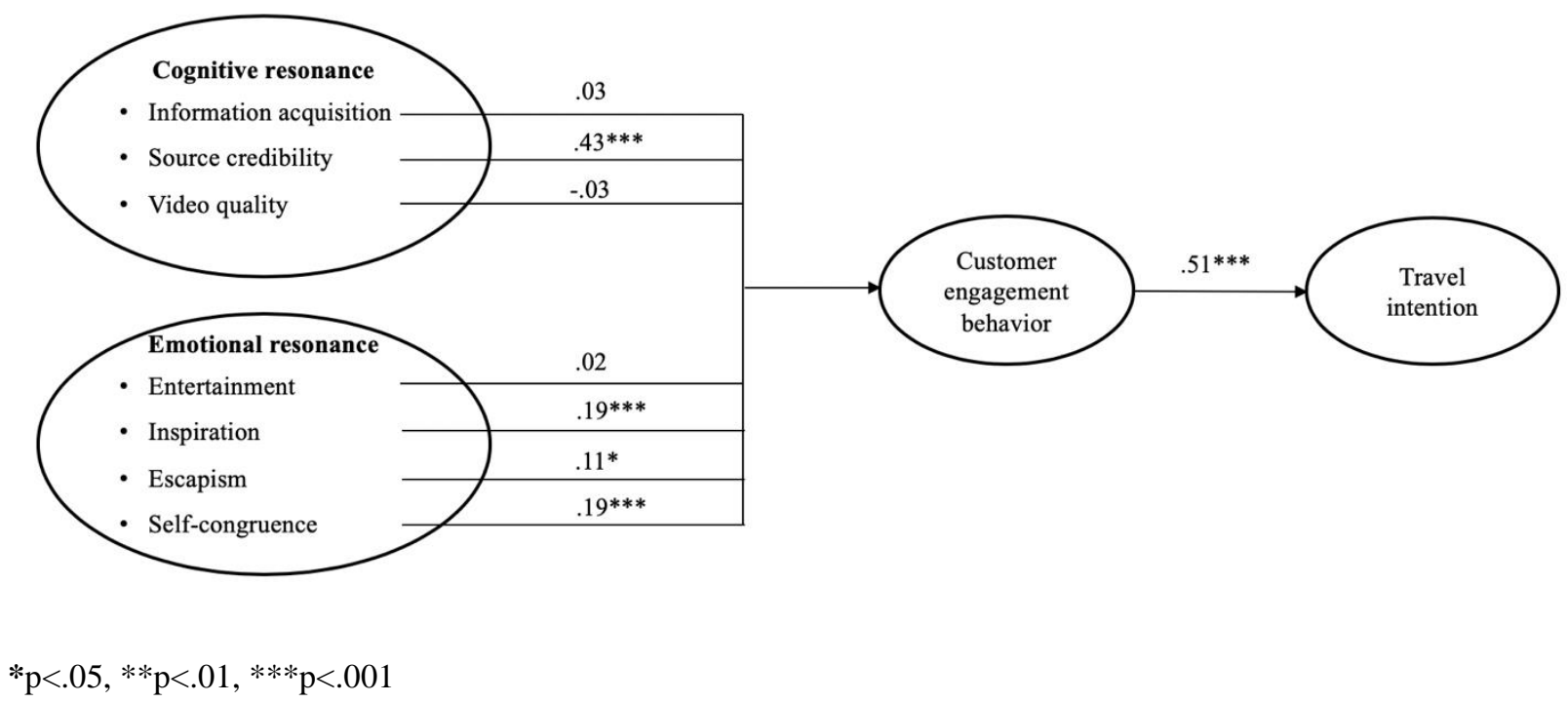

Fig.2. Regression results.

\section{Conclusions and implications}

With the growing needs of short video consumption, both hospitality and tourism academia and industry call for a more in-depth understanding of how to assess and improve audiences' 
watching experiences of travel vlogs, which contributes to their travel intention to the destination (Henderson, 2018; Lodha and Philip, 2019). This study made one of the first attempts to examine the effects of watching experiences on CEB in travel vlogs and further their behavior intention. While some studies have investigated how online shared travel videos affect touristic experiences (Tussyadiah and Fesenmaier, 2009) and how online celebrities impact customers' purchase intention (e.g. hotel booking intention) (Zhang et al., 2019), the present study, adopting the theory of resonance (Giorgi, 2017; McDonnell et al., 2017; Snow et al., 1986), emphasizes how cognitive and emotional factors influence CEB with travel vlogs and travel intentions, providing a more holistic and explicit framework as a foundation for future research of online videos.

The most interesting finding of the present research is that in terms of cognitive resonance, only one factor, source credibility, significantly influences CEB. It is also the strongest predictor among all other factors. This implies that the convincible image of a travel vlogger drives audiences' willingness to further engage with the content. Such a finding can be explained by the theory of cognitive authority (Rieh and Danielson, 2007; Wilson, 1983), which argued that those who are perceived to be knowledgeable and trustworthy would be considered as cognitive authorities. Given that an online environment is uncontrolled and hard to make judgement (Rieh, 2002), those worth-of-belief images are important for people to determine whether they wanted to engage with the information they received from travel vlogs or not. Moreover, travel experiences are considered as personal, subjective, and intangible (O'dell, 2007), which are hard to be assessed aforehand as tangible goods. The travel vlogs filmed by credible sources can effectively assist audiences in evaluating the tourism destination and further influence their willingness to engage. The dominant role of source credibility not only validates findings in communication studies that audiences tend to be largely influenced by credible speakers (Hovland and Weiss, 1951), but also extends previous media research by linking source credibility to customer engagement behavior.

Second, in contrast to previous studies advocating that information acquisition and video quality have significant impacts on CEB (Dobrian et al., 2011; Khan, 2017; McDonnel et al., 2017; Rafaeli, 1986), the present study found that these variables were not significant predictors in the context of travel vlogs. Although information acquisition is often found to be one of the most important motives of people's engagement in media consumption, the current study 
revealed that even when travel vlogs offered ample and useful travel-related information, audiences may still not show engagement behaviors. A potential explanation for such a finding is that customers are flooded with fragmented information everywhere due to increased popularity of self-media in people's daily lives. The volume of the unsystematic information may cause customers' aesthetical fatigue and thus weaken the impact of information acquisition on the engagement behavior. Additionally, the insignificant relationship between video quality and CEB implies that the quality of vlogs (e.g. clear image and smooth flow) was not a strong motivator for people to recommend them to others. It may be because travel vlogs are known for the natural and personal filming style (Wiens, 2013). The shooting equipment used by travel vloggers is usually just a cell phone and vloggers often improvise without much preparation when making vlogs. Audiences may thus expect to watch the "real stories" even when they are not perfect in quality. These specialties differ travel vlogs from other types of travel videos and help to explain why video quality did not significantly predict CEB.

The results also revealed that more factors from emotional resonance influenced CEB. In the context of travel vlogs, cognitive factors were overridden by those experiential ones (i.e., inspiration and escapism), indicating that an online environment highlights people's experiences, which makes the audiences to shift from focusing on mundane rational attributes to addressing their emotional involvement. However, different from prior studies (Khan, 2017; Lee and Ma, 2012; Park et al., 2009), entertainment turned out to be an insignificant predictor of CEB. This finding, nevertheless, mirrors the research by De Vries et al. (2012), which found that entertainment did not significantly influence the number of likes and the number of comments people made on social networking sites. Entertainment, emphasizing the hedonic gratification, is associated with more lighthearted and playful tendencies (Oliver and Raney, 2011). A plausible explanation is that CEB may be triggered by deeper and longer-lasting factors that go beyond the initial superficial amusement or entertainment.

Lastly, this research revealed that CEB, as manifested in word-of-mouth intention, indeed effectively bridged customer watching experiences of travel vlogs and their travel intention. The more effort customers devoted to advocating their favorable travel vlogs, the higher travel intentions they seem to develop, advancing prior research which suggested that CEBs affect behavioral intention (e.g. consumers' purchase intention) in hospitality and tourism (e.g. Ahn and Back, 2018), marketing (e.g. Yusuf and Busalim, 2018), and public affairs (e.g. Kang, 2014). 


\subsection{Theoretical implications}

Despite the increasing number of journal articles tackling media consumption, only a few were related to vlogs in a travel context. Therefore, this study yields significant and unique contributions to the literature in the fields of media consumption, tourism destination, and customer engagement. First, as one of the pioneer studies on travel vlogs, this research empirically examined how audiences evaluate their watching experiences of online video products. The academic attention on vlogs can date back to a decade ago when Burgess and Green (2009) described the popularity of vlog channels and how people were attracted to their real and natural content instead of fabricated television productions. In particular, travel videos have been examined for their impacts on tourists' travel experiences (Tussyadiah and Fesenmaier, 2009). Although travel vlogs have been recognized as one of the most important genres of online videos by industry practitioners and websites managers (e.g. YouTube), limited academic research has considered it as a specific study object (Lodha and Philip, 2019). The present research thus makes timely and meaningful contributions to the knowledge of travel vlog and empirically supports that the optimal watching experiences can enhance CEB, further influencing customers' behavior intention towards destinations.

Second, this research extends previous literature on the theory of resonance by applying it to an online media environment of travel vlogs. Stems from sociology, the theory of resonance was often used to understanding how culture, organizational frame, and marketing brands influence people (Benford and Snow, 2000; Keller, 2001; Schudson,1989). The present research applied it to a new field, in order to dissect how the resonance mechanism may work in the context of travel vlogs. While most of the previous studies only considered either the cognitive or the emotional aspect of resonance, this research, echoing the research stream of McDonnel et al. (2017) and Giorgi (2017), incorporated both aspects to provide a more holistic understanding of the phenomenon. The results advance the development of resonance theory by presenting a twodimensional conceptualization for the drivers of CEB in the context of travel vlogs.

Third, the results of the present research add new insight into customer engagement literature by exploring the antecedents and downstream behavior of CEB in the online media environment of travel vlogs. Although previous researchers have explored the motives (Kabadayi and Price, 2014; Khan, 2017) and the consequential factors of online users' engagement behaviors 
respectively (Fang et al., 2017; Jang et al., 2009), limited studies have examined the drivers and downstream behaviors simultaneously with few exceptions (Islam et al., 2018). This research extends prior literature by conceptualizing the drivers of engagement behavior into two categories (cognitive and emotional factors) and by emphasizing the salient role of engagement behaviors in driving travel intentions.

\subsection{Practical implications}

This research generates abundant practical implications for destination marketing and management, travel vloggers/influencers, and small and medium-sized enterprises (SMEs) in the travel and hospitality. First, this research provides hospitality and tourism entrepreneurs with great insight into how travel vlogs could influence prospective customers. Although travel vlogs are booming over recent years, most of them were based on vloggers' personal interests or intrinsic benefits. This research offered empirical evidence for the opportunities to affect prospective tourists' visit intention by leveraging travel vlogs. Such evidence suggests that hospitality and tourism management (e.g. hotels, restaurants, and travel agencies) could consider promote their product and service by collaborating with travel vloggers who already have many loyal followers. For example, Marriott has partnered with influencers in the production of travel vlogs (Cvent Guest, 2019) for marketing purposes. In particular, small and medium-sized enterprises (SMEs) that have limited marketing resources are encouraged to adopt this strategy and work with travel vloggers to increase brand awareness and to reach untapped market segments.

Second, this research provides vloggers with a better understanding of what watching experiences the audiences are willing to engage with further. Specifically, travel vlogs that are credible, inspiring, congruent with audiences' image, and make people feel detached from daily life are more favored. In particular, a credible image of the travel vlogger is the strongest factor driving audiences' engagement behavior. Therefore, vloggers with a vested interest in travels are suggested to keep their vlogs as authentic and trustworthy as possible. For instance, vloggers should authentically document their actual travel experiences no matter they are good or bad. Vloggers who pursue a long-term success have to abandoned pretenses and be real in front of the camera (Ip, 2019). Indeed, popular travel vloggers attracted and maintained over millions of followers by not only sharing their expert advice on how and where to travel, but also through 
their authentic persona (Jean, 2019). In addition, among the studied factors representing cognitive and emotional resonance, more emotional factors turned out to have significant impacts on CEB than cognitive factors did, indicating that travel vlog audiences are more likely to be influenced by sentimental feelings rather than rational facts. Therefore, to enhance engagement behaviors, travel vloggers are recommended to convey their intrinsic passion and enthusiasm through the vlogs to create an emotional connection with the audiences. For those vloggers who are at the early stage of their career and are eager to attract more fans, this research suggests that instead of only focusing on video quality, they should also strive to stage a watching experience that meets viewers' desire of escaping the daily routines.

Third, this research provides destination marketing and management with a better understanding of how travel vlogs could attract prospective tourists to visit the destination. In the last few years, online travel videos, especially travel vlogs became very powerful in people's decision-making processes (Guest Blogger, 2017; Think with Google, 2016). This research not only offers empirical evidence for the remarks but also reveals the mechanism behind this phenomenon by identifying CEB as a bridging factor. Destination marketing organizations (DMOs) are suggested to take advantage of video marketing, and actively promote destinations to prospective tourists by inspiring and/or incentivizing them to engage with the vlogs. Additionally, DMOs are encouraged to build a long-term relationship with audiences by creating original vlogs to regularly promote destination-relevant content. In fact, some destination organizations in China have gradually recognized the benefits to attract tourists by using a popular mobile short video application called Douyin. Through this approach, DMOs are able to maintain their interactivity with prospective tourists, establish their own "traffic pool" for followers, and create an ideal environment to encourage prospective tourists' engagement behaviors such as recommendation and endorsement.

\subsection{Limitations and suggestions for future research}

This research has some limitations that would provide opportunities for future research. First, in this study, participants were asked to recall their most memorable travel vlogs. While this critical incident technique is a commonly used method in experience research, the authors cannot completely rule out the possibility of memory bias. Future studies should consider qualitative 
research methods (e.g. interviews, focus groups, content analysis of online user-generated data) that are well recognized for their power to elicit respondents' in-depth emotional responses.

Second, this research represents one of the first studies that investigated factors influencing people's engagement in travel vlogs. There exist other factors that may moderate the studied relationships, such as personalities and culture values, which provide potential avenues for future research.

Third, this research focuses on respondents' experiences with travel vlogs. It is worth noting that for different types of destinations, the studied factors may weigh differently in driving people's experiences and behaviors. For example, inspiration and escapism may be more valued for vlogs featuring magnificent natural scenery, while information acquisition and source credibility may be more relevant for vlogs introducing heritage sites. It will be interesting for future research to explore such potential variance. 
References:

Ahn, J. and Back, K. J. (2018), “Antecedents and consequences of customer brand engagement in integrated resorts", International Journal of Hospitality Management, Vol. 75, pp. 144-152.

Bagozzi, R. P. and Yi, Y. (1988), "On the evaluation of structural equation models", Journal of the Academy of Marketing Science, Vol. 16 No. 1, pp. 74-94.

Bail, C. A. (2016), "Cultural carrying capacity: organ donation advocacy, discursive framing, and social media engagement", Social Science and Medicine, Vol. 165, pp. 280-288.

Baldus, B. J., Voorhees, C. and Calantone, R. (2015), “Online brand community engagement: scale development and validation", Journal of Business Research, Vol. 68 No. 5, pp. 978985.

Benford, R. D. and Snow, D. A. (2000), "Framing processes and social movements: an overview and assessment", Annual Review of Sociology, Vol. 26, pp. 611-639.

Berger, J. (2014), "Word of mouth and interpersonal communication: a review and directions for future research", Journal of Consumer Psychology, Vol. 24 No. 4, pp. 586-607.

Berlo, D. K., Lemert, J. B. and Mertz, R. J. (1969), "Dimensions for evaluating the acceptability of message sources”, Public Opinion Quarterly, Vol. 33 No. 4, pp. 563-576.

Bhattacherjee, A. and Sanford, C. (2006), "Influence processes for information technology acceptance: an elaboration likelihood model”, MIS Quarterly, Vol. 30 No. 4, pp. 805825.

Bijmolt, T. H., Leeflang, P. S., Block, F., Eisenbeiss, M., Hardie, B. G., Lemmens, A. and Saffert, P. (2010), “Analytics for customer engagement”, Journal of Service Research, Vol.13 No. 3, pp. 341-356.

Böttger, T., Rudolph, T., Evanschitzky, H. and Pfrang, T. (2017), “Customer inspiration: conceptualization, scale development, and validation”, Journal of Marketing, Vol. 81 No. 6, pp. 116-131.

Brodie, R. J., Hollebeek, L. D., Jurić, B. and Ilić, A. (2011), “Customer engagement: conceptual domain, fundamental propositions, and implications for research", Journal of Service Research, Vol. 14 No. 3, pp. 252-271. 
Buhrmester, M., Kwang, T. and Gosling, S. D. (2011), “Amazon's mechanical turk: a new source of inexpensive, yet high-quality, data?", Perspectives on Psychological Science, Vol. 6 No. 1, pp. 3-5.

Burgess, J. and Green, J. (2009), "The entrepreneurial vlogger: beyond the professional/amateur Divide", in Snickars, P. and Vonderau, P. (Eds), The YouTube reader, National Library of Sweden, pp. 89-10.

Burgoon, J. K. and Hale, J. L. (1984), “The fundamental topoi of relational communication”, Communication Monographs, Vol. 51, pp. 193-214.

Chen, Y. C., Shang, R. A. and Li, M. J. (2014), “The effects of perceived relevance of travel blogs' content on the behavioral intention to visit a tourist destination", Computers in Human Behavior, Vol. 30, pp. 787-799.

Choi, H. and Kandampully, J. (2019), "The effect of atmosphere on customer engagement in upscale hotels: an application of SOR paradigm”, International Journal of Hospitality Management, Vol. 77, pp. 40-50.

Csikszentmihalyi, M. (1990), Flow: The Psychology of Optimal Experience: Steps toward Enhancing the Quality of Life, Harper and Row, New York, NY.

Cvent Guest (2019), “4 creative ways to use influencer marketing for hotels”, Cvent, available at: https://www.cvent.com/en/blog/hospitality/4-creative-ways-hotels-can-work-influencers (accessed 05 April 2020).

Dessart, L., Veloutsou, C. and Morgan-Thomas, A. (2015), “Consumer engagement in online brand communities: a social media perspective", Journal of Product and Brand Management, Vol. 24 No. 1, pp. 28-42.

De Vries, L., Gensler, S. and Leeflang, P. S. (2012), "Popularity of brand posts on brand fan pages: an investigation of the effects of social media marketing”, Journal of Interactive Marketing, Vol. 26 No. 2, pp. 83-91.

Djafarova, E. and Rushworth, C. (2017), 'Exploring the credibility of online celebrities' Instagram profiles in influencing the purchase decisions of young female users", Computers in Human Behavior, Vol. 68, pp. 1-7.

Dobrian, F., Sekar, V., Awan, A., Stoica, I., Joseph, D., Ganjam, A., Zhan, J. and Zhang, H. (2011), "Understanding the impact of video quality on user engagement", $A C M$ SIGCOMM Computer Communication Review, Vol. 41 No. 4, pp. 362-373. 
Elliot, A. J. (1997), "Integrating the "classic" and "contemporary" approaches to achievement motivation: a hierarchical model of approach and avoidance achievement motivation", in Maehr, M. L. and Pintrich, P. R. (Eds), Advances in Motivation and Achievement, JAI Press, Greenwich, pp. 143-179.

Fang, J., Zhao, Z., Wen, C. and Wang, R. (2017), "Design and performance attributes driving mobile travel application engagement", International Journal of Information Management, Vol. 37 No. 4, pp. 269-283.

Giorgi, S. (2017), "The mind and heart of resonance: the role of cognition and emotions in frame Effectiveness", Journal of Management Studies, Vol. 54 No. 5, pp. 711-738.

Glucksman, M. (2017), “The rise of social media influencer marketing on lifestyle branding: a case study of Lucie Fink", Elon Journal of Undergraduate Research in Communications, Vol. 8 No. 2, pp. 77-87.

Gretzel, U. (2018), "Influencer marketing in travel and tourism”, in Sigala, M. and Gretzel, U. (Eds), Advances in Social Media for Travel, Tourism and Hospitality: New Perspectives, Practice and Cases, Routledge, New York, pp. 147-156.

Griffith, M. and Papacharissi, Z. (2010), "Looking for you: an analysis of video blogs", First Monday, Vol. 15 No. 1, available at: https://firstmonday.org/ojs/index.php/fm/article/download/2769/2430 (accessed 19 March 2020).

Guest Blogger (2017), "How YouTube vloggers are changing the travel industry", Wersm, available at: https://wersm.com/youtube-vloggers-changing-travel-industry/ (accessed 05 April 2020).

Han, H. and Back, K. J. (2008), "Relationships among image congruence, consumption emotions, and customer loyalty in the lodging industry", Journal of Hospitality and Tourism Research, Vol. 32 No. 4, pp. 467-490.

Henderson, P. (2018), "Video marketing in travel-10 key insights", Marketing and Growth Hacking, available at: https://blog.markgrowth.com/video-marketing-in-travel-10-keyinsights-a64fdcffa465 (accessed 08 November 2019).

Hollebeek, L. D. (2011), "Demystifying customer brand engagement: exploring the loyalty nexus", Journal of Marketing Management, Vol. 27 No. (7/8), pp. 785-807.

Holmqvist, J., Ruiz, C. D. and Peñaloza, L. (2019), "Moments of luxury: hedonic escapism as a 
luxury experience", Journal of Business Research, in press.

Hosany, S. and Witham, M. (2010), "Dimensions of cruisers' experiences, satisfaction, and intention to recommend", Journal of Travel Research, Vol. 49 No.3, pp. 351-364.

Hovland, C. I. and Weiss, W. (1951), "The influence of source credibility on communication Effectiveness", Public Opinion Quarterly, Vol. 15 No. 4, pp. 635-650.

Ip, E. (2019), “6 Engagement Marketing Lessons from Successful Video Bloggers”, Marketo, available at: https://blog.marketo.com/2016/04/6-engagement-marketing-lessons-fromsuccessful-video-bloggers.html (accessed 10 March 2020).

Islam, J. U., Rahman, Z. and Hollebeek, L. D. (2018), "Consumer engagement in online brand communities: a solicitation of congruity theory", Internet Research, Vol. 28 No. 1, pp. 23-45.

Jang, S., Bai, B., Hu, C. and Wu, C. M. E. (2009), "Affect, travel motivation, and travel intention: a senior market", Journal of Hospitality and Tourism Research, Vol. 33 No. 1, pp. 51-73.

Jean, K. (2019), “15 Amazing travel vloggers”, Filtergrade, available at: https://filtergrade.com/amazing-travel-vloggers/ (accessed 19 March 2020).

Jung, N. Y. and Seock, Y. K. (2017), "Effect of service recovery on customers' perceived justice, satisfaction, and word-of-mouth intentions on online shopping websites", Journal of Retailing and Consumer Services, Vol. 37, pp. 23-30.

Kabadayi, S. and Price, K. (2014), "Consumer-brand engagement on Facebook: liking and commenting behaviors", Journal of Research in Interactive Marketing, Vol. 8 No. 3, pp. 203-223.

Kahn, W. A. (1990), "Psychological conditions of personal engagement and disengagement at Work", Academy of Management Journal, Vol. 33 No. 4, pp. 692-724.

Kang, M. (2014), "Understanding public engagement: conceptualizing and measuring its influence on supportive behavioral intentions", Journal of Public Relations Research, Vol. 26 No. 5, pp. 399-416.

Keller, K. L. (2001), Building Customer-based Brand Equity: A Blueprint for Creating Strong Brands, Marketing Science Institute, Cambridge, MA.

Keller, K. L. (2009), "Building strong brands in a modern marketing communications environment", Journal of Marketing Communications, Vol. 15 No. (2-3), pp. 139-155. 
Khan, M. L. (2017), "Social media engagement: what motivates user participation and consumption on YouTube?", Computers in Human Behavior, Vol. 66, pp. 236-247.

Kim, H. and Choi, B. (2013), "The influence of customer experience quality on customers' behavioral intentions", Services Marketing Quarterly, Vol. 34 No. 4, pp. 322-338.

Kim, H. and Fesenmaier, D. R. (2008), "Persuasive design of destination web sites: an analysis of first impression”, Journal of Travel Research, Vol. 47 No. 1, pp. 3-13.

Kumar, V., Aksoy, L., Donkers, B., Venkatesan, R., Wiesel, T. and Tillmanns, S. (2010), "Undervalued or overvalued customers: capturing total customer engagement value", Journal of Service Research, Vol. 13 No. 3, pp. 297-310.

Law, R., Leung, D. and Chan, I. C. C. (2019), "Progression and development of information and communication technology research in hospitality and tourism", International Journal of Contemporary Hospitality Management, Vol. 32 No. 2, pp. 511-534.

Lee, C. S. and Ma, L. (2012), "News sharing in social media: the effect of gratifications and prior experience", Computers in Human Behavior, Vol. 28 No. 2, pp. 331-339.

Lodha, R. and Philip, L. (2019), "Impact of travel blogs and vlog on decision-making among the students of Bangalore", International Journal of Scientific Research and Review, Vol. 7 No. 3, pp. 2279-2543.

Lou, C. and Yuan, S. (2019), "Influencer marketing: how message value and credibility affect consumer trust of branded content on social media", Journal of Interactive Advertising, Vol. 19 No. 1, pp. 58-73.

Marketing Science Institute (2010), 2010-2012 Research Priorities: A Guide to MSI Research Programs and Procedures, Marketing Science Institute, Cambridge, MA.

McDonnell, T. E. (2014), "Drawing out culture: productive methods for measuring cognition and resonance", Theory and Society, Vol. 43, pp. 247-274.

McDonnell, T. E., Bail, C. A. and Tavory, I. (2017), “A theory of resonance”, Sociological Theory, Vol. 35 No. 1, pp. 1-14.

McKnight, D. H., Choudhury, V. and Kacmar, C. (2002), "The impact of initial consumer trust on intentions to transact with a web site: a trust building model”, The Journal of Strategic Information Systems, Vol. 11 No. (3-4), pp. 297-323.

Mohammed Abubakar, A. (2016), "Does eWOM influence destination trust and travel intention: a medical tourism perspective”, Economic Research-Ekonomska Istraživanja, Vol. 29 
No. 1, pp. 598-611.

Munar, A. M. and Jacobsen, J. K. S. (2014), "Motivations for sharing tourism experiences through social media", Tourism Management, Vol. 43, pp. 46-54.

National Community Media Alliance (NCMA) (2018). "25 YouTube video ideas to help you make viral videos", NCMA, available at: https://ncmagroup.com/2018/07/03/25-youtubevideo-ideas-to-help-you-make-viral-videos/ (accessed 12 December 2019).

Nov, O., Naaman, M. and Ye, C. (2010), “Analysis of participation in an online photo-sharing community: a multidimensional perspective", Journal of the American Society for Information Science and Technology, Vol. 61 No. 3, pp. 555-566.

O'dell, T. (2007), “Tourist experiences and academic junctures”, Scandinavian Journal of Hospitality and Tourism, Vol. 7 No. 1, pp. 34-45.

Oh, C., Roumani, Y., Nwankpa, J. K. and Hu, H. F. (2017), "Beyond likes and tweets: consumer engagement behavior and movie box office in social media", Information and Management, Vol. 54 No. 1, pp. 25-37.

Oliver, M. B. and Raney, A. A. (2011), "Entertainment as pleasurable and meaningful: identifying hedonic and eudaimonic motivations for entertainment consumption. Journal of Communication, Vol. 61 No. 5, pp. 984-1004.

Oxford English Dictionary (1996), Oxford University Press, Oxford.

Palmgreen, P., Wenner, L. A. and Rayburn, J. D. (1980), "Relations between gratifications sought and obtained: a study of television news", Communication Research, Vol. 7 No. 2, pp. 161-192.

Papacharissi, Z. and Mendelson, A. (2011), “Toward a new (er) sociability: uses, gratifications and social capital on Facebook", in Papathanassopoulos, S. (Ed), Media Perspectives for the 21st Century, Routledge, New York, pp. 212-230.

Park, N., Kee, K. F. and Valenzuela, S. (2009), "Being immersed in social networking environment: facebook groups, uses and gratifications, and social outcomes", CyberPsychology and Behavior, Vol. 12 No. 6, pp. 729-733.

Pihlaja, S. (2014), Antagonism on YouTube: Metaphor in Online Discourse, Bloomsbury Academic, New York, NY.

Pine, B. J. and Gilmore, J. H. (1998), "Welcome to the experience economy”, Harvard Business Review, Vol. 76, pp. 97-105. 
Polletta, F. (2009), It was Like a Fever: Storytelling in Protest and Politics, University of Chicago Press, Chicago, IL.

Rafaeli, A. (1986), "Employee attitudes toward working with computers", Journal of Organizational Behavior, Vol. 7 No. 2, pp. 89-106.

Rahmi, Y., Sekarasih, L. and Sjabadhyni, B. (2016), "The influence of beauty vlog on perceived source credibility and purchase intention", Makara Hubs-Asia, Vol. 20 No. 2, pp. 13-23.

Rich, B. L., Lepine, J. A. and Crawford, E. R. (2010), "Job engagement: antecedents and effects on job performance", Academy of Management Journal, Vol. 53 No. 3, pp. 617-635.

Rieh, S. Y. (2002), "Judgment of information quality and cognitive authority in the Web", Journal of the American Society for Information Science and Technology, Vol. 53 No. 2, pp. 145-161.

Rieh, S. Y. and Danielson, D. R. (2007), "Credibility: a multidisciplinary framework”, Annual Review of Information Science and Technology, Vol. 41 No. 1, pp. 307-364.

Sara. (2016), "Make awesome video with 12 best travel vlogging tips", Flyingchalks, available at: https://flyingchalks.com/en/travelogue/98/travel-tips-12-travel-vlogging-tips-that-willhelp-you (accessed 15 February 2020).

Schouten, A. P., Janssen, L. and Verspaget, M. (2020), "Celebrity vs. Influencer endorsements in advertising: the role of identification, credibility, and Product-Endorser fit. International Journal of Advertising, Vol. 39 No. 2, pp. 258-281.

Schudson, M. (1989), "How culture works: perspectives from media studies on the efficacy of Symbols", Theory and Society, Vol. 18 No. 2, pp. 153-180.

Scoble, R. and Israel, S. (2006), Naked Conversations: How Blogs are Changing the Way Business Talk with Customers, John Wiley, Hoboken, NJ.

Shang, S. S., Wu, Y. L. and Sie, Y. J. (2017), "Generating consumer resonance for purchase intention on social network sites", Computers in Human Behavior, Vol. 69, 18-28.

Sirgy, M. J. and Su, C. (2000), "Destination image, self-congruity, and travel behavior: toward an integrative model", Journal of Travel Research, Vol. 38 No. 4, pp. 340-352.

Snow, D. A., Rochford Jr, E. B., Worden, S. K. and Benford, R. D. (1986), "Frame alignment processes, micromobilization, and movement participation", American Sociological Review, Vol. 51 No. 4, pp. 464-481.

So, K. K. F., King, C. and Sparks, B. (2014), "Customer engagement with tourism brands: scale 
development and validation. Journal of Hospitality and Tourism Research, Vol. 38 No. 3, pp. 304-329.

Sokolova, K. and Kefi, H. (2019), "Instagram and YouTube bloggers promote it, why should I buy? How credibility and parasocial interaction influence purchase intentions", Journal of Retailing and Consumer Services, in press.

Solis, B. (2010). “Social Media’s Critical Path: Relevance to Resonance to Significance”, Harvard Business Review Blog Network, available at: https://hbr.org/2010/07/socialmedias-critical-path-re (accessed 22 March 2020).

Stamboulis, Y. and Skayannis, P. (2003), "Innovation strategies and technology for experiencebased tourism", Tourism Management, Vol. 24 No. 1, pp. 35-43.

Think with Google (2014), "YouTube data", available at: https://www.thinkwithgoogle.com/consumer-insights/travel-content-takes-off-onyoutube/ (accessed 20 July 2019).

Think with Google (2016), "How micro-moments are reshaping the travel customer Journey”, available at: https://think.storage.googleapis.com/docs/micro-momentsreshaping-travel-customer-journey-b.pdf (access 20 July 2019).

Thrash, T. M. and Elliot, A. J. (2003), "Inspiration as a psychological construct", Journal of Personality and Social Psychology, Vol. 84 No. 4, pp. 871-889.

Tussyadiah, I. P. and Fesenmaier, D. R. (2009), “Mediating tourist experiences: access to places via shared videos", Annals of Tourism Research, Vol. 36 No. 1, pp. 24-40.

Van Doorn, J., Lemon, K. N., Mittal, V., Nass, S., Pick, D., Pirner, P. and Verhoef, P. C. (2010), "Customer engagement behavior: theoretical foundations and research directions", Journal of Service Research, Vol. 13 No. 3, pp. 253-266.

Vivek, S. D. (2009), “A scale of consumer engagement (Unpublished doctoral dissertation)”, University of Alabama, Tuscaloosa, available at: https://ir.ua.edu/handle/123456789/603 (accessed 12 December 2019).

Wheeless, V. E., Witt, P. L., Maresh, M., Bryand, M. C. and Schrodt, P. (2011), "Instructor credibility as a mediator of instructor communication and students' intent to persist in college", Communication Education, Vol. 60 No. 3, pp. 314-339.

Wiens, M. (2013), “How to make travel videos for YouTube (and grow your channel)?”, Migrationology, available at: https://migrationology.com/travel-videos-youtube/ 
(accessed 8 November 2019).

Wilson, P. (1983), Second-hand Knowledge: An Inquiry into Cognitive Authority. Greenwood Press, Westport, CT.

Xiao, M., Wang, R. and Chan-Olmsted, S. (2018), "Factors affecting YouTube influencer marketing credibility: a heuristic-systematic model”, Journal of Media Business Studies, Vol. 15 No. 3, pp. 188-213.

Yang, S. U., Kang, M. and Johnson, P. (2010), "Effects of narratives, openness to dialogic communication, and credibility on engagement in crisis communication through organizational blogs", Communication Research, Vol. 37 No. 4, pp. 473-497.

Yusuf, A. S. and Busalim, A. H. (2018), "Influence of e-WOM engagement on consumer purchase intention in social commerce", Journal of Services Marketing, Vol. 32 No. 4, pp. 493-504.

Zha, X., Yang, H., Yan, Y., Liu, K. and Huang, C. (2018), "Exploring the effect of social media information quality, source credibility and reputation on informational fit-to-task: moderating role of focused immersion", Computers in Human Behavior, Vol. 79, pp. 227-237.

Zhang, L., Kuo, P. J. and McCall, M. (2019), "Microcelebrity: the impact of information source, hotel type, and misleading photos on consumers' responses", Cornell Hospitality Quarterly, Vol. 60 No. 4, pp. 285-297. 